\title{
Population Based Cancer Incidence In 15 Districts of three Geographical Region, Mountain, Hills and Tarai for 2013-2014 In Nepal
}

\section{Krishna Prasad Subedi*'Laxmi Narayan Singh, Binay Thakur, KK Pradhananga, Chin Bahadur Pun}

B. P. Koirala Memorial Cancer Hospital, Bharatpur, Chitwan, Nepal

*Corresponding author:-krishnasubedidr@gmail.com

\section{ABSTRACT}

Now more and more cancers are being diagnosed in Nepal. But it is hard to assess the burden of cancer in national context based on available data. The available hospital based information neither shows the magnitude of the problem nor there has been any community-based study in the past. First time in Nepal population based Cancer registry (PBCR) was started in 15 districts of different geographical region i.e. Himal, Pahad, Tarai, which covered the $25.8 \%$ of total population of the nation. Therefore, outcome of this study can be used to infer an overall situation of cancer in Nepal.

In the year 2013-14, cancer cases were reported from data source institutions for the process of population based cancer registration. Among them the cases were verified by name, age, sex and disease i.e. topography/morphology. Cases were collected

from projected areas and multiple entry were excluded from data base and total $5089(2469+2620)$ cases were analyzed for the purpose. The mean age at diagnosis in 2013 was 53.9 years and 53.2 years in 2014, whereas; mean age in average for 2013-14 was 53.6 years.

In the year 2013, the most frequent form of cancer for both sexes was bronchus \& lung $15.7 \%$, followed by cervix uteri $11.0 \%$, and breast $7.6 \%$. Among the female cases cervix uteri cancer $20.0 \%$ was the most frequent, followed by breast $13.5 \%$ and bronchus \& lung cancer $12.9 \%$. Similarly, bronchus \& lung cancer $15.8 \%$ was the most common cancer among males, followed by stomach $6.1 \%$ and larynx cancer $4.3 \%$. The most prevalent age group in male 70-74 years $19.9 \%$, while in female it was in same age group $70-74$ years $13.4 \%$.

In the year 2014, the leading sites of cancer for both sexes was bronchus \& lung 13.7\%, followed by cervix uteri $10.5 \%$, and breast $9.5 \%$. Among the female cases cervix uteri cancer $18.0 \%$ was the most frequent, followed by breast $15.5 \%$ and bronchus \& lung cancer $11.8 \%$. Similarly, bronchus \& lung cancer $16.5 \%$ was the most common cancer among males, followed by stomach $7.4 \%$ and larynx cancer $5.3 \%$. The most prevalent age group in male $70-74$ years $11.3 \%$, while in female it was in same age group $60-64$ years $12.3 \%$. The present data provide population based cancer burden in Nepal. According to findings, cancer of bronchus\& lung was the most common topography of cancer followed by cervix uteri and breast for both sex in 2013-14.

Keywords : Cancer registration, Hospital based, Incidence, Population based, Topography

\section{INTRODUCTION}

Hospital based cancer registry has been started in Nepal since 2003 by B.P. Koirala Memorial cancer Hospital (BPKMCH). However, population based cancer registry (PBCR) was not started until 2013. To address the need of population based cancer registry, Cancer Prevention Control and Research Department of BPKMCH initiated the population based cancer registry in 2013. Population based cancer registry is 
the process of recording new cancer patients from defined population. The information from cancer registry provides a data source for planning and evaluation of cancer control activities and epidemiological studies. The PBCR provides incidence rates, characteristics of the population concerned and clues to etiology and prevention.

Cancer is a emerging public health problem in developing countries. The magnitude of the problem of cancer in terms of its large number, warrant $s$ particular attention of policy makers to evolve national programs of the action to develop, implement, coordinate and also to evaluate the cancer control activities in individual countries (Gupta et al., 1993).

According to GLOBOCAN 2012, an estimated 14.1 million new cancer cases and 8.2 million cancer related deaths occurred. Compared with 12.7 million and 7.6 million, respectively in 2008 (Ferlay et al., 2012)The importance of cancer registry data for development of national cancer control programs has already been stressed in the context of South Asia (Bhurgri, 2004).

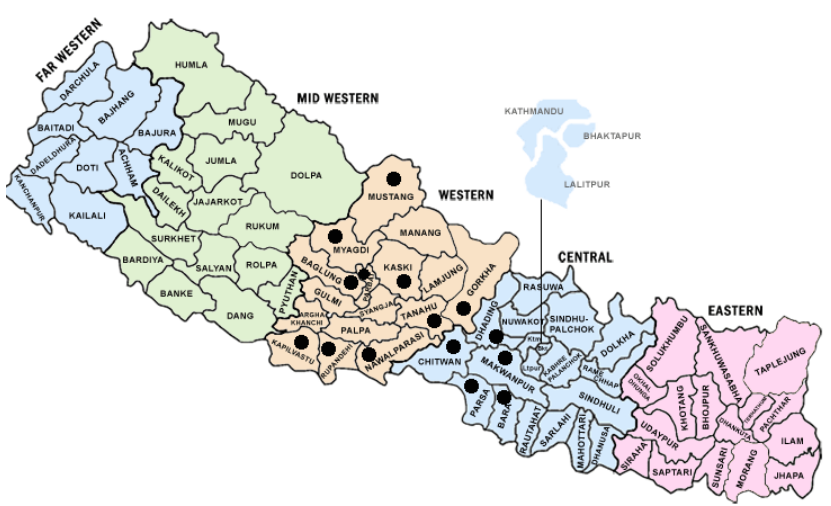

Figure 1. Three Geographical area of 15 district, Mountain, Hills and Tarai
Table 1. Area and population covered by this study

\begin{tabular}{llll}
\hline District's Name & Male & Female & Total \\
\hline Chitwan & 298400 & 297681 & 658114 \\
Makwanpue & 243921 & 238877 & 528160 \\
Bara & 361920 & 347026 & 708947 \\
parsa & 322851 & 305630 & 628481 \\
Nawalparasi & 350017 & 352031 & 702048 \\
Rupandehi & 456337 & 445481 & 901818 \\
Kapilvastu & 306323 & 295986 & 602309 \\
Dhading & 204735 & 207581 & 412317 \\
Gorkha & 165830 & 175941 & 341771 \\
Myagdi & 65686 & 69928 & 135613 \\
Tanahun & 183533 & 195926 & 378559 \\
Baglung & 154590 & 166206 & 320796 \\
Parbat & 89095 & 95287 & 320796 \\
Kaski & 235364 & 240541 & 475905 \\
Mustang & 9017 & 8146 & 17163 \\
& 3447619 & 3442268 & 6889887 \\
\hline
\end{tabular}

Total population of Nepal: 2,66,208,09 (2068)

Total Population of study area : 68,89,887

Coverage $25.88 \%$ of total population

\section{MATERIALS AND METHODS}

This is retrospective analysis, the information of all new cancer cases of all age group were collected and recorded between $1^{\text {st }}$ January to $31^{\text {st }}$ December 201314 . The mortality data due to cancer was also collected from office of the vital events registration unit of each DDC/VDCs/ Municipalities of relevant districts. Collected data were coded according to ICD O $3 \mathrm{dr}$ and ICD-10 published by IARC/WHO and proceed for data analysis using SPSS 19.0. 
Data Sources

- District Hospital, Medical college and other hospitals.

- District Health and Public Health Office and other relevant organizations.

- DDC /VDC/Municipality, i.e. office of vital event registration.

- Privet hospitals, Diagnostic lab, hospice etc.

Table 2. Data for Most Prevalent Cancers in 15 District for Both sex- 2013

\begin{tabular}{llcc}
\hline ICD-10 & Topography & $\#$ & $\%$ \\
\hline C34 & Bronchus and & 390 & 15.7 \\
& lung & & \\
C53 & Cervix uteri & 272 & 11.0 \\
C50 & Breast & 188 & 7.6 \\
C16 & Stomach & 138 & 5.5 \\
C56 & Ovary & 106 & 4.2 \\
C32 & Larynx & 94 & 3.8 \\
C67 & Bladder & 93 & 3.7 \\
C71 & Brain & 70 & 2.8 \\
C22 & Liver & 64 & 2.5 \\
C23 & Gall bladder & 62 & 2.4 \\
- & Other cancer & 992 & 40.1 \\
Total & & 2469 & 100.0 \\
\hline
\end{tabular}

Table 3. Data for Most Prevalent Cancers in 15 District for Male - 2013

\begin{tabular}{llcc}
\hline ICD-10 & Topography & $\#$ & $\%$ \\
\hline C34 & Bronchus and lung & 215 & 19.3 \\
C16 & Stomach & 83 & 7.4 \\
C32 & Larynx & 59 & 5.3 \\
C67 & bladder & 58 & 5.2 \\
C22 & Liver & 36 & 3.2 \\
C15 & Esophagus & 34 & 3.1 \\
C49 & Connective & 34 & 3.1 \\
& subcutaneous \& other & & \\
& soft tissues & & \\
C71 & Brain & 33 & 3.0 \\
- & Unspecified & 29 & 2.7 \\
C23 & Rectum & 27 & 2.4 \\
- & Other cancer & 505 & 45.3
\end{tabular}

Total

1113

100.0

Table 4. Data for Most Prevalent Cancers in 15 district for Female -1013

\begin{tabular}{llcc}
\hline ICD-10 & Topography & $\#$ & $\%$ \\
\hline C53 & Cervix uteri & 272 & 20.1 \\
C50 & Breast & 184 & 13.6 \\
C34 & Bronchus and & 175 & 12.9 \\
& lung & & \\
C56 & Ovary & 105 & 7.7 \\
C71 & Brain & 37 & 2.7 \\
C23 & Gall bladder & 37 & 2.7 \\
C32 & Larynx & 35 & 2.5 \\
C67 & Bladder & 35 & 2.5 \\
C20 & Rectum & 28 & 2.0 \\
C15 & Esophagus & 26 & 1.9 \\
- & Other cancer & 422 & 31.4 \\
Total & & 1356 & 100.0 \\
\hline
\end{tabular}

Table 5. Data for Most Prevalent Cancers in 15 district for Both sex -2014

\begin{tabular}{llcc}
\hline ICD-10 & Topography & $\#$ & $\%$ \\
\hline C34 & Bronchus and & 361 & 13.7 \\
& lung & & \\
C53 & Cervix uteri & 277 & 10.5 \\
C50 & Breast & 249 & 9.6 \\
C16 & Stomach & 144 & 5.4 \\
C56 & Ovary & 123 & 4.6 \\
C23 & Gall bladder & 110 & 4.2 \\
C20 & Rectum & 86 & 3.3 \\
C32 & Larynx & 85 & 3.2 \\
C67 & Bladder & 76 & 2.9 \\
C71 & Brain & 73 & 2.7 \\
- & Other cancers & 1036 & 39.5 \\
Total & & 2620 & 100.0 \\
\hline
\end{tabular}

Table 6. Collected Data for Most Prevalent Cancers in 15 district for Male -1014

\begin{tabular}{llcc}
\hline $\begin{array}{l}\text { ICD- } \\
10\end{array}$ & Topography & $\#$ & $\%$ \\
\hline C34 & $\begin{array}{l}\text { Bronchus and } \\
\text { lung }\end{array}$ & 180 & 16.7 \\
& & &
\end{tabular}




\begin{tabular}{clcc} 
C16 & Stomach & 81 & 7.4 \\
C32 & Larynx & 58 & 5.4 \\
C67 & Bladder & 55 & 5.0 \\
C71 & Brain & 39 & 3.5 \\
C20 & Rectum & 39 & 3.5 \\
C22 & Liver & 38 & 3.4 \\
C61 & Prostate gland & 37 & 3.4 \\
- & Unspecified & 35 & 3.2 \\
& Colon & & \\
C18 & Colon & 34 & 3.1 \\
- & Other cancer & 492 & 45.4 \\
Total & & 1088 & 100.0 \\
\hline
\end{tabular}

Table 7. Data for Most Prevalent Cancers in 15 district for Female -1014

\begin{tabular}{clcc}
\hline $\begin{array}{c}\text { ICD- } \\
10\end{array}$ & Topography & $\#$ & $\%$ \\
\hline C53 & Cervix uteri & 277 & 18.2 \\
C50 & Breast & 238 & 15.6 \\
C34 & Bronchus and & 181 & 11.8 \\
& lung & & \\
C56 & Ovary & 123 & 8.0 \\
C23 & Gall bladder & 80 & 5.2 \\
C20 & Stomach & 63 & 4.1 \\
C71 & Rectum & 47 & 3.0 \\
C32 & Thyroid & 37 & 2.4 \\
C22 & Brain & 34 & 2.2 \\
C27 & Larynx & 27 & 1.7 \\
- & Other cancers & 425 & 27.8 \\
Total & & 1532 & 100.0 \\
\hline
\end{tabular}

III. Results

During the study period net 5089 cases were recorded as summarized in Tab 2-7. Female cases $54.9 \%$ were more common than in male 45.1\%. for 2013. Similarly, in the year of 2014, female $58.5 \%$ ware more than male $41.5 \%$. The number of cases by site (ICD-10) and percentage of various cancer cases for males and females are given in Table.

In addition, data for the age distribution of the most common cancers are given in figure 1 and 2 for males and females, separately.

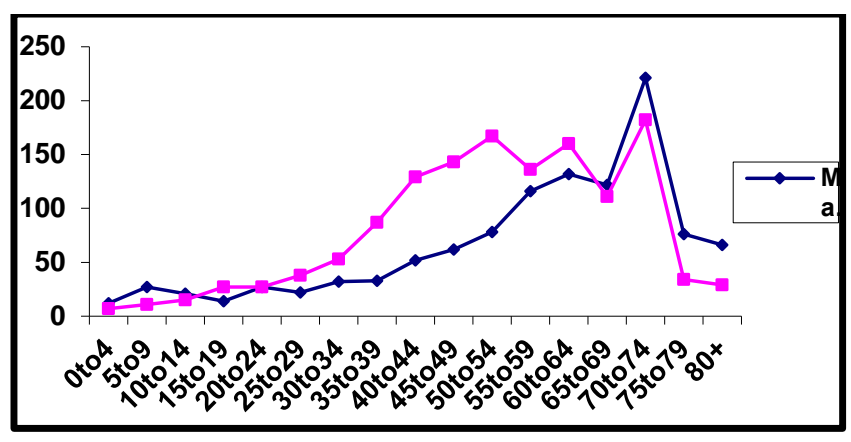

Figure1. age distribution of cancer cases for both sex 2013

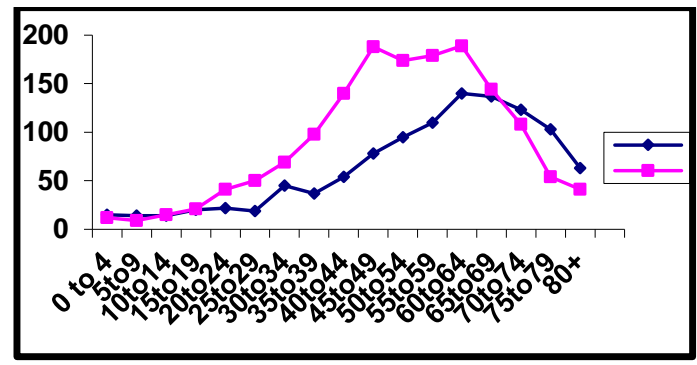

Figure 2. Age Distribution of Cancer cases for both sex - 2014

\section{Discussion}

This study was undertaken at BP Koirala memorial cancer hospital, Bharatpur, Chitwan, Nepal, Which is only national cancer institute of the nation, using secondary data of national cancer registry programme and data sources institution of study areas.

In this study,bronchus \& lung cancer generally predominating in males, presumably because of smoking habits, and latter in females (Curado et al., 2007., Moor at al., 2010., Forman et al., 2012). A survey in rural communities of Nepal bt Pandey et al. (1988) showed that in the 20+ years age group 85.4\% of men and $62.4 \%$ of women were tobacco users. The prevalence of smoke less tobacco use, as well as smoking, is high, particularly among males and disadvantaged groups (Sinha at al.., 2012). More recently, it was documented that older women are also very likely to smoke, especially those with a lower socioeconomic status (Pandey and Lin, 2013). Awareness of lung cancer by tobacco use and other risk factors varied with socioeconomic status amongst residents of Pokhara, Despite their awareness of smoking as a risk factor for lung cancer, most of them 
still continue to smoke (Chawla et al., 2010). Furthermore, even medical student perceptions about the cause of lung cancer may be influenced by their smoking behavior and there was little knowledge of public health measures for smoking control (Khatiwada et al., 2012).

In this study cancer of cervix uteri was the second leading cancer site for both sex and top cancer topography for female. Among females cancer of cervix uteri is a common cancer site for developing countries but in developed countries breast cancer ranked as a leading cancer. (Curado et al.,2007; Moore et al., 2010; Forman et al ., 2012). There is an urgent need for a reinvigorated and tailored approach to cervix cancer prevention among the educated youth in India, Nepal and Srilanka (joy et al., 2011). From this data we have found a significant increase in cancer of cervix uteri in the future, suggesting the need for more focus and resource allocation on cervical cancer screening and treatment (Sathin et al., 2013). Self- collected sampling methods should be the subject of additional research in Nepal for screening HR-HPV, associated with pre-cancer lesions and cancer, in women rural communities with limited access to health services (Johnson et al ., 2014). In the context of limited screening services in Nepal, the efforts should be to reduce the diagnostic delay especially patient and health care provider delay for early detection and reduction of mortality rate of cervical cancer (Gyenwali et al., 2014). Risk factors for cancer of cervix uteri like early age a marriage, and early age at first birth, multiparity, poor genital hygiene and infection with HPV virus infection are common in Nepal. Health education programs which are effective not only in increasing knowledge about cervical cancer and pap smear test but also effective in positively changing attitude towards the test should be organized to increase pap smear coverage (Ranabhat et al., 2014).

Breast cancer was the third most common cancer for both sex and second leading cancer site in female for 2015. Cancer of breast proved to have overtaken cervical cancer in terms of incidence, as in the majority of countries of Asia (Curado et al., 2007; Moore et al., 2010; Forman et al., 2012). The fact that young Nepalese women account for over one quarter of all female breast cancers, many being diagnosed at an advanced stage (Sharma et al., 2005; Thapa et al., 2013) is of particular importance. The level of awareness of breast cancer, including knowledge of warning signs and BSE (breast self examination), is sub-optimal among Nepalese women (Sathian et al., 2014). Low knowledge on breast cancer, risk factors and screening practice among female groups (shrestha, 2012). Community interventions have been a focus in Bangladesh (Ansink et al., 2008) and Kolkaata (Basu et al., 2006) and deserve emphasis in the Nepali context. In both breast and cervical cancer cases compliance with both screening guidelines and subsequent referral and treatment are necessary (Dinshaw et al., 2007a;2007b). It Should be noted that BSE has been validated in the Nepalese setting (Tara et al., 2008).

\section{Acknowledgements}

The author would like to thanks all the data source institutions and their staffs for providing valuable information towards this research.

\section{REFERENCES}

[1]. Ansink AC, Tolhurst R, Haque R, et al. (2008). Cervical cancer in Bangladesh: community perceptions of cervical cancer and cervical cancer screening. Trans R Soc Trop Med Hyg,102, 499505.

[2]. Basu P, Sarkar S, Mukherjee S,et al (2006). Women's perceptions and social barriears determine compliance to cervical screen: result 
from a population based study in India. Cancer Detect Prev, 30,369-74.

[3]. Bhandari GP, Angdembe MR, Dhimal M,Neupane S, Bhusal C 8662 Asian Pacific Journal of Cancer Prevention, Vol 16, 2015 (2014). State of noncommunicable diseases in Nepal. BMC Public Health, 14, 23.

[4]. Bhurgi Y (2004). Karachi Cancer Registry Dataimplications for the National Cancer Control Program of Pakisthan. Asian J Cancer Prev,5,7782.

[5]. Binu VS, Chandrashekhar TS, Subba SH, et al. (2007). Cancer pattern in Western Nepal: a hospital based retrospective study, Asian Pac J cancer Prev, 8, 183-6.

[6]. Chawla R, Sathian B,Mehra A,(2010). Awareness and assessment of risk factors for lung cancer in residents of Pokhara Valley, Nepal. Asian Pac J cancer Prev, 11, 1789-93.

[7]. Curado MP, Edwards B,Shin HR, et al (Eds) (2007). Cancer Incidence in Five Continents Vol.IX.IARC Scientific Publications No. 160, IARC, Lyon.

[8]. Dinshaw K, Mishra G, Shastri S, et al. (2007a). Determinants of compliance in a cluster randomized controlled trial on screening of breast and cervix cancer in

[9]. Mumbai, India.1.compliance to screening. Onchology,73,145-53.

[10]. Dinshaw K, Mishra G, Shastri S, et al. (2007a). Determinants of compliance in a cluster randomized controlled trial on screening of breast and cervix cancer in Mumbai, India.2.compliance to referral and treatment. Onchology,73,145-61.

[11]. Ferlay J, Soerjomataram I, Ervik $M$, et al (2012).GLOBOCAN 2012 vl.0, cancer Incidence and Mortality Worldwide: IARC CancerBase No. 11 [Internet]. Lyon, France: International Agency for Research on Cancer; 2013. Available from:http:// globocan.iarc.fr,accessed on 26.12.2015.
[12]. Ghumare SS, Cunningham JE (2007). Breast cancer trends in Indian residents and emigrants protend an emerging epidemic for India. Asian Pac J cancer Prev, 8, 507-12.

[13]. Joy T, Sathian B,Bhattarai C, Chacko J (2011). Awareness of cervix cancer risk factors in educated youth: a cross sectional, Questionnaire based survey in Indi, Nepal and Sri Lanka. Asian Pac J Cancer Prev, 12, 1707-12.

[14]. Khatiwada P, Kayastha SR, Pant P, et al 92012). Understanding of tobacco and lung cancer among medical students in Kathmandu University School of Medical Sciences (KUSMS). Kathmandu Univ Med J, 10, 60-5.

[15]. Moore M, Ariyante Y, Badar F, et al (2010).Cancer epidemiology and control in southern Asia - past, present and future. Asian Pac J Cancer Prev, 11,17-32.

[16]. National Cancer Registry Programme Report of Hospital Based Cancer Registry. B.P. Koirala Memorial Cancer Hospital cancer prevention, control and research department. 2003;

[17]. National Cancer Registry Programme Report of Hospital Based Cancer Registry. B.P. Koirala Memorial Cancer Hospital cancer prevention, control and research department. 2004;

[18]. National Cancer Registry Programme Report of Hospital Based Cancer Registry. B.P. Koirala Memorial Cancer Hospital cancer prevention, control and research department. 2005;

[19]. National Cancer Registry Programme Report of Hospital Based Cancer Registry. B.P. Koirala Memorial Cancer Hospital cancer prevention, control and research department. 2006;

[20]. National Cancer Registry Programme Report of Hospital Based Cancer Registry. B.P. Koirala Memorial Cancer Hospital cancer prevention, control and research department. 2007;

[21]. National Cancer Registry Programme Report of Hospital Based Cancer Registry. B.P. Koirala Memorial Cancer Hospital cancer prevention, control and research department. 2008; 
[22]. National Cancer Registry Programme Report of Hospital Based Cancer Registry. B.P. Koirala Memorial Cancer Hospital cancer prevention, control and research department. 2009;

[23]. National Cancer Registry Programme Report of Hospital Based Cancer Registry. B.P. Koirala Memorial Cancer Hospital cancer prevention, control and research department. 2010;

[24]. National Cancer Registry Programme Report of Hospital Based Cancer Registry. B.P. Koirala Memorial Cancer Hospital cancer prevention, control and research department. 2011;

[25]. National Cancer Registry Programme Report of Hospital Based Cancer Registry. B.P. Koirala Memorial Cancer Hospital cancer prevention, control and research department. 2012;

[26]. National Cancer Registry Programme Report of

[27]. Population Based Cancer Registry. B.P. Koirala Memorial Cancer Hospital cancer prevention, control and research department. 2013-14;

[28]. Pandeya DR, Mittal A, Sathian B, Bhatta B, (2014). Role of hyperinsulinemia in increased risk of prostate cancer: a case control study from Kathmandu Valley. Asian Pac J Cancer Prev, 15, 1031-3.

[29]. Pradhananga KK, Baral M, Shrestha BM 92009). Multi-institution hospital-based cancer incidence data for Nepal: an initial report. Asian Pac J cancer Prev, 10, 259-62.

[30]. Ranabhat S, Tiwari M, Dhungana G, Shrestha R (2014). Association of knowledge, attitude and demographic variables with cervical Pap smear practice in Nepal. Asian Pac J Cancer Prev, 15, 8905-10.

[31]. Sah Jk, Singh YP, Ghimire B, (2015). Presentation and outcomes of gastric cancer at a University Teaching Hospital in Nepal. Asian Pac J cancer Prev, 15, 5385-8).

[32]. Sathian B, Bhatt CR, Jayadevan S, et al (2010). Prediction of cancer cases for a hospital in Nepal: astatistical modeling. Asian Pac J prev, 11, 441-5.
[33]. Sathian B, FazilA, Sreedharan J, et al (2013). Statistical modeling and forecasting of cervix cancer cases in radiation oncology treatment: hospital based study from Western Nepal. Asian Pac J cancer Prev, 14, 2097-100.

[34]. Sathian B, Nagaraja SB, Banerjee I, et al (2014). Awareness of breast cancer warning signs and screening methods among female residents of Pokhara Valley, Nepal. Asian Pac J Cancer Prev, 15, 4723-6.

[35]. Sharma A, Bhandari R, Gilbert D, Sharma AK (2005). Bening and malignant breast disease presenting to Bhaktapur cancer Hospital. Kathmandu Univ Med J, 3, 384-7.

[36]. Sinha DN, Bajracharya B, Khadka BB, et al (2012).Smokeless tobacco use in Nepal. Indian J Cancer, 49, 352-6.

[37]. Tara S, Agrawal CS, Agrawal A (2008). Validating breast self examination of Nepal: a population based study. Kathmandu Univ Med J, 6, 89-93.

[38]. Thapa B, Sayami P, (2014). Low lung cancer resection rates in a tertiary level thoracic center in Nepal-where lies our problem? Asian Pac J cancer Prev, 15, 175-8.

[39]. Thapa B, Singh Y, Sayami P, Shrestha UK, Sapkota R, Sayami G, (2013). Breast cancer in young women from a low risk population in Nepal. Asian Pac J Cancer Prev, 14, 5095-9.

\section{Cite this article as :}

Krishna Prasad Subedi, Laxmi Narayan Singh, Binay Thakur, KK Pradhananga, Chin Bahadur Pun, " Population Based Cancer Incidence In 15 Districts of three Geographical Region, Mountain, Hills and Tarai For 2013-2014 In Nepal", International Journal of Scientific Research in Science and Technology (IJSRST), Online ISSN : 2395-602X, Print ISSN : 2395-6011, Volume 6 Issue 3, pp. 219-225, May-June 2019. Available at doi : https://doi.org/10.32628/IJSRSET196346 Journal URL : http://ijsrst.com/IJSRSET196346 